\title{
Article \\ Vibroacoustic Assessment of an Innovative Composite Material for the Roof of a Coupe Car
}

\author{
Nunziante Cascone ${ }^{1}$, Luca Caivano ${ }^{2}$, Giuseppe $\mathrm{D}^{\prime}$ Errico $^{2}$ and Roberto Citarella ${ }^{1, *(\mathbb{D})}$ \\ 1 Department of Industrial Engineering, University of Salerno, Via Giovanni Paolo II 132, \\ 84084 Fisciano, Salerno, Italy; n.cascone6@studenti.unisa.it \\ 2 Fiat Chrysler Automobiles (FCA) S.p.A., Via ex Aeroporto, 80038 Pomigliano D'Arco, Napoli, Italy; \\ luca.caivano@fcagroup.com (L.C.); giuseppe.derrico@fcagroup.com (G.D.) \\ * Correspondence: rcitarella@unisa.it
}

Citation: Cascone, N.; Caivano, L.; D'Errico, G.; Citarella, R. Vibroacoustic Assessment of an Innovative Composite Material for the Roof of a Coupe Car. Appl. Sci. 2021, 11, 1128. https://doi.org/ 10.3390/app11031128

Academic Editor: Francois Gautier

Received: 4 January 2021

Accepted: 22 January 2021

Published: 26 January 202

Publisher's Note: MDPI stays neutral with regard to jurisdictional claims in published maps and institutional affiliations.

Copyright: (C) 2021 by the authors. Licensee MDPI, Basel, Switzerland. This article is an open access article distributed under the terms and conditions of the Creative Commons Attribution (CC BY) license (https:// creativecommons.org/licenses/by/ $4.0 /)$.

\begin{abstract}
The objective of this paper is the vibroacoustic evaluation of an innovative material for a sports car roof, aiming at replacing fiberglass composite materials. Such evaluation was carried out using numerical and experimental analysis techniques, with cross-comparison between the corresponding results. The innovative material under analysis is a composite material, with a thermoplastic polypropylene matrix and reinforcement made of cellulose fibers. In order to validate the virtual dynamic modeling of the new material, the inertance on different points of some sheets made of the material under analysis was evaluated by an in-house made experimental activity, performed in the CRF (Fiat Research Center) test room, and cross-compared with corresponding results from a numerical analysis performed with the MSC Nastran software. Then, a realistic model of the car roof of the Alfa Romeo 4C car, made with the new material, was implemented and analyzed from the vibroacoustic point of view. The mere switch to the new material, with no changes in the geometry/structure of the car roof, did not allow preserving the original values of static rigidity, dynamic rigidity, and configuration of modal shapes. For this reason, a geometric/structural optimization of the component was performed. Once the new geometry/structure was defined, a vibroacoustic analysis was carried out, checking for a possible coupling between the fluid cavity modes and the structure car body modes. Finally, the vibroacoustic transfer functions to the driver's ear node were assessed, considering two different excitation points on the structure. The excellent damping capacity of the proposed material led to an improvement in the vibroacoustic transfer functions and to a reduction in the weight of the pavilion.
\end{abstract}

Keywords: vibroacoustic evaluation; sports car roof; biocomposite materials; FEM; noise reduction

\section{Introduction}

The vibroacoustic analysis of structural components, used in aircraft [1], spacecraft [2], land vehicles [3], and ships [4,5], plays a vital role in the design of these systems with regard to human health and living comfort.

The numerical tools of the Finite Element Method [6,7] and Boundary Element Method [8] have been applied extensively for modeling acoustic problems. Such numerical techniques are adopted stand-alone or in conjunction (hybrid methods) [9].

New materials as alternatives to petroleum-based composite materials are needed due to the adverse effects of the latter on nature. On the other hand, there is a need to characterize and evaluate such new alternative materials to be effectively used in practical applications.

Nowadays, in the automotive field, it is usual to see isotropic materials for vibrating plates replaced by composite materials, also due to their superior damping characteristics [10], even if their vibroacoustic characteristics have not yet been extensively examined. In particular, the main challenge in implementing a new composite roof for a car body 
is related not only to its structural assessment but also to guarantee its compliance with vibroacoustic requirements.

In Genovese et al. [11], the traditional metallic roof has been compared with the newly proposed solution in terms of structural and vibroacoustic performances. The different stiffness and the different mass of the roof change the vibrational behavior of the entire vehicle and consequently its transmission loss.

Lightweight components are typically stiff and thin-walled and thus tend to have significant sound radiation. Due to structure complexity, composites exhibit great variability in mechanical properties and need to be analyzed on the basis of different ply angles, wall thickness, and damping ratio [12]. Namely, using fiber-reinforced materials offers a wide range of possibilities for adjusting their properties, such as stiffness and damping, by manipulating layup, fiber, and matrix material, or fiber volume content [13]. With such numerous degrees of freedom when designing a composite, there is a need for efficient simulation methods for vibroacoustic analyses involving complex multi-physical models, possibly with allowance for fluid-structure interaction.

Fiber-reinforced composites exhibit random fiber orientations due to the manufacturing tolerances. The study in [14] concerns with a numerical investigation of the vibrational behavior of the long fiber-reinforced composites under uncertainty in fiber orientations. A numerical case study is used to illustrate the features of the method, where the impact of the uncertainty in fiber orientations on the natural frequencies and mode shapes of a rectangular composite plate with nominal orientation is investigated.

The vibroacoustic behavior of bio-composites, including damping and elastic properties, sound absorption, and transmission loss levels, are investigated in [15]. Despite having less detrimental environmental effects and thorough availability, natural fibers are still unsuitable for wide implementation in industrial components. Some shortcomings, such as the presence of moisture contents, thicker diameter, and lower antifungus quality, hold up the progress of natural fiber composites in staying competitive with synthetic composites. The review in [16] aims at investigating the acoustic absorption behavior of natural fiber composites due to the incorporation of granular materials. The possible influential factors of fibers and grains were described for the enhancement of low-frequency acoustic absorption of the composites.

The impact of elastic parameter uncertainty on the natural frequency and the radiated acoustic power of laminated composite plates is investigated in [17]. Numerical results show that the natural frequencies and the radiated acoustic powers are strongly affected by uncertainty in input parameters.

Coupled vibroacoustic analyses of plates produced from composite materials can be performed by using finite element analysis software. The study in [18] has been carried out for E-glass/Epoxy, Kevlar/Epoxy and Carbon/Epoxy plates with different ply angles and numbers of ply. The effects of composite material, ply orientation, and number of layers on coupled vibroacoustic characteristics of plates have been statistically analyzed for various combinations.

A review of major developments in numerical and experimental methods for vibroacoustic analysis of cavities for predicting low-frequency sound field or noise is provided in [19]. Details of formulation of both the acoustic and coupled vibroacoustic problems are presented. Applications of cavity acoustic to the problem of vehicle noise are also reviewed. Mode shapes of the composite panel are dependent on the fiber orientation, as shown in [20], where modal analysis for different fiber orientations $\left(\right.$ at $0^{\circ}, 30^{\circ}, 45^{\circ}, 60^{\circ}$, and $\left.90^{\circ}\right)$ is carried out by using ABAQUS software.

The objective of this work is the vibroacoustic evaluation of PP 23 CF (a polypropylene matrix reinforced with a percentage of vegetable fibers) for the sports car roof, aiming at replacing fiberglass composite materials (the current car pavilion is made of a thermosetting fiberglass composite material).

In the present case study, the design activities have been focused on the optimization of the geometries and masses under service loads of flatwise panels composed of elements 
made of new generation composite materials, with the aim to make lighter the existing components of a car.

In the following, the reported graphs lack some numerical values because of a nondisclosure agreement with FCA.

\section{Material and Methods}

\subsection{Fiberglass Composites}

Nowadays, fiberglass molded composite materials are widely used in the automotive industry. These composite materials are, in particular, used for car panels, and they are competitive compared to aluminum alloy for small or medium volumes since for high volumes, metal alloys exhibit lower production costs.

Furthermore, fiberglass composite materials have numerous positive aspects that have increased their appeal for this kind of applications (Figure 1).

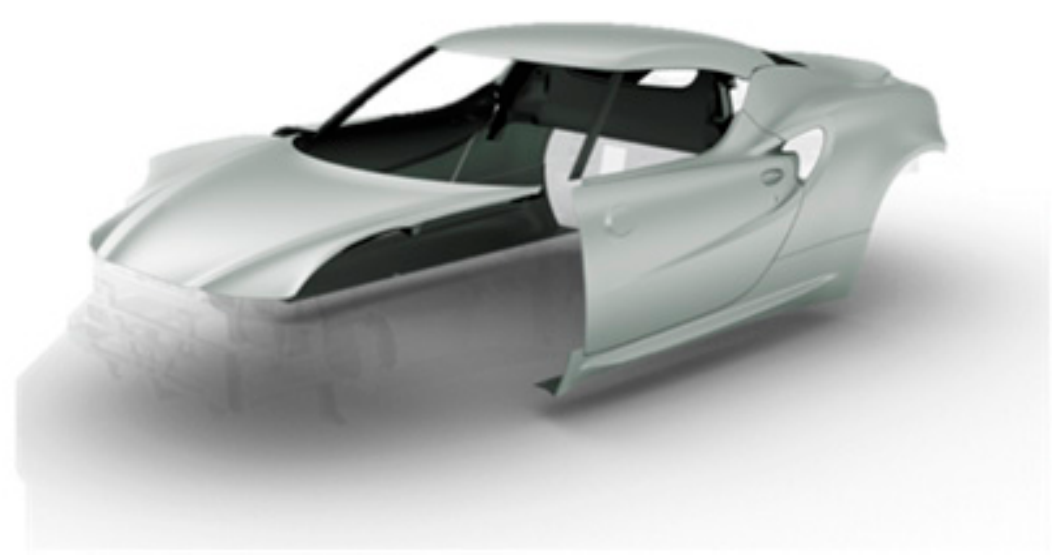

Figure 1. Fiberglass composite components of the Alfa Romeo 4C car.

On the other hand, fiberglass composites cannot be easily cut. In order to avoid the diffusion and inhalation of dust they require special precautions and to operate in a protected environment. The polymerization reaction is not reversible, in fact, they do not regain their original liquid form through heating, as thermoplastic materials usually do, therefore, fiberglass scrap cannot be melted and remodeled as often happens in plastic recycling.

Current waste management of fiberglass composite materials is carried out according to the following practice:

- Disposal in landfills (certainly not the optimal solution, also due to the nonbiodegradability of the material),

- Incineration, with the enormous problem of smoke pollution,

- Recycling through regrinding: The composite is ground to be reused as a filler (usually in building materials),

- Recycling by pyrolysis, by means of which the polymer is thermally decomposed in the absence of oxygen, the fibers are separated and used again as fillers (this solution is, however, economically not very convenient),

- Recycling through acid digestion, through chemical dissolution of the composite (this process is, however, economically prohibitive).

\subsection{Biocomposite Materials}

In January 2007, the European Commission proposed a reduction in the transport sector connected to GHG (greenhouse gas) by redefining the emissions target of new vehicles at $95 \mathrm{~g}$ of $\mathrm{CO}_{2}$ per $\mathrm{km}$, starting from the beginning of 2021.

The LIFE BIOBCOMPO project, from which this work is developed, aims to reduce the environmental impact of new vehicles through innovative low-density thermoplastic composites, derived from renewable resources (bio-based). 
The main goals are:

- Very low-density thermoplastic materials that allow saving weight compared to traditional composites, with a proportional reduction in $\mathrm{CO}_{2}$ emissions,

- Replacement of conventional mineral fibers with bio-based fibers, thus promoting the use of more sustainable, biodegradable resources, minimizing the environmental impact,

- Demonstrate that these new technologies are applicable on an industrial scale and overcome the problems associated with the industrialization of the new solutions proposed.

The most promising biocomposite developed is a polypropylene (PP) matrix reinforced with a percentage of vegetable fibers. This material has been applied to the injection molding of some components of the Alfa Romeo Giulia FCA car, which are normally made of glass fibers (GF).

The material analyzed in this work is PP $23 \mathrm{CF}$, in which the abbreviation stands for:

- Polypropylene (PP) matrix, a thermoplastic polymer characterized by a high rupture load, low density, good thermal, and abrasion resistance;

- $\quad$ Reinforcement in vegetable cellulose fibers (cellulose fiber, CF).

\subsection{Experimental and Numerical Setup}

The inertance values on different points of some sheets made of PP 23 CF were evaluated by an in-house made experimental activity, performed at CRF (Fiat Research Center, Turin, Italy) test room, and by a numerical analysis, performed with the MSC Nastran software, obtaining a satisfactory agreement and consequently validation of the virtual modeling of the new material. Then, the car roof of the Alfa Romeo $4 \mathrm{C}$ car, made with PP 23 CF, was modeled and analyzed from the vibroacoustic point of view.

A mere switch to the new material, with no changes in the geometry/structure of the car roof, would not have preserved the values of static rigidity, dynamic rigidity, and the configuration of modal shapes of the fiberglass car roof. For this reason, a geometric/structural optimization of the component was necessary.

Once the new geometry/structure was defined, a vibroacoustic analysis was carried out, consisting of the following phases: The fluid cavity of the passenger compartment, the seats, and the dashboard of the vehicle were modeled with the ANSA software (a multidisciplinary CAE pre-processing tool that provides all the necessary functionality for full-model build up, from CAD data to ready-to-run solver input file), then a modal analysis was carried out to check any coupling of the fluid cavity modes with the structure car body modes, in order to decide if a weak rather than a strong coupled analysis was needed. Finally, the vibroacoustic transfer functions to the driver's ear node were assessed considering two different excitation points on the structure.

\section{Damping Coefficient Assessment for the New Biocomposite Material}

\subsection{Procedure}

The mechanical properties of the biocomposite material, reinforced with vegetable fibers, were measured at CRF in Turin, obtaining a Young modulus and a density lower than traditional composite materials.

For damping measurements of different types of materials, in particular polymers and composite materials, the CRF Composite Materials Laboratory is equipped with a machine (Figure 2) that provides the damping loss factor, $\eta$, and the damping ratio, $\zeta$. 


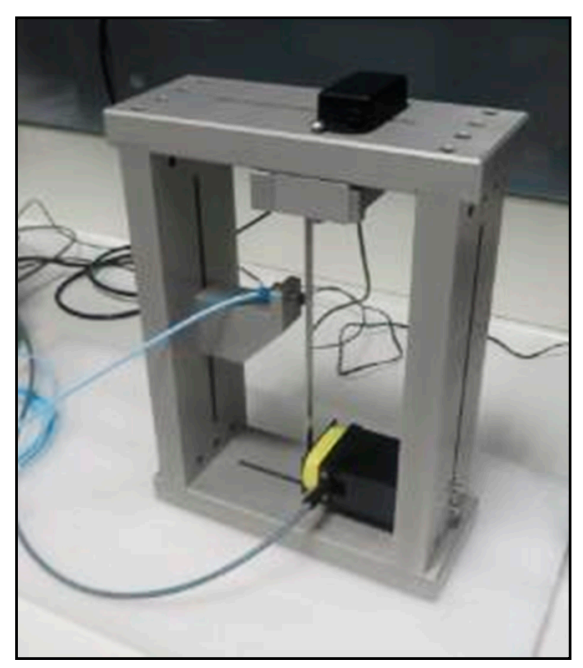

Figure 2. Machine for damping measurement.

These parameters are obtained according to ASTM E756 "Standard Test Method for Measuring Vibration-Damping Properties of Materials". The starting data are acquired in the time domain as an oscillating response of the specimen. The frequency analysis returns the values of loss factor, $\eta$, and damping ratio, $\zeta$, vs. frequency for the material under examination.

The aforementioned procedure is based on the following steps:

- the specimen is clamped at one end in a fixed-free configuration,

- an electromagnetic coil actuator applies an excitation force that causes the specimen to vibrate,

- two measuring sensors provide displacement and acceleration of a specific point.

The analysis software enables the control of the whole measurement process, driving the forcing signal and analyzing the output signal in the time/frequency domain. Typically, the vibrating modes of the bar are sufficiently separated in frequency to allow an easy estimate of the damping parameters, in accordance with ASTM E756.

The damping parameters are determined through the half power method, in which an intermediate parameter is evaluated by:

$$
Q^{-1}=\frac{\Delta f_{n(-3 d b)}}{f_{n}}
$$

where $f_{n}$ is the resonant frequency and $\Delta f_{n(-3 d b)}$. is the half-power bandwidth of the n-th mode estimated at $-3 \mathrm{~dB}$ with respect to the peak at $f_{n}$.

According to the Complex-Spring model, the loss factor $\eta$ is determined from the relationship:

$$
\eta=\sqrt{1-\frac{1}{4}\left[2-\left(\frac{1}{Q}\right)^{2}\right]^{2}} .
$$

According to the Kelvin-Voigt model, the damping ratio $\zeta$ is determined by the relationship:

$$
\zeta=\frac{1}{2} \sqrt{\sqrt{4+\frac{8}{Q^{2}}}-2-\left(\frac{1}{Q^{2}}\right)}
$$

The software uses the two previous exact formulas for the calculation of $\eta$ and $\zeta$.

The input signal is of simple harmonic type, with fixed amplitude and frequency, and the FRF (Frequency Response Function) is measured point by point for each frequency value considered. 
The measurement with this type of input proceeds in two phases: A first exploration, carried out with a large frequency range, $(0-2000 \mathrm{~Hz})$, with the purpose of identifying the resonance peaks (Figure 3), followed by a detailed analysis carried out around the resonance peaks with very small frequency increases in order to accurately collect the most significant data relating to the individual modes.

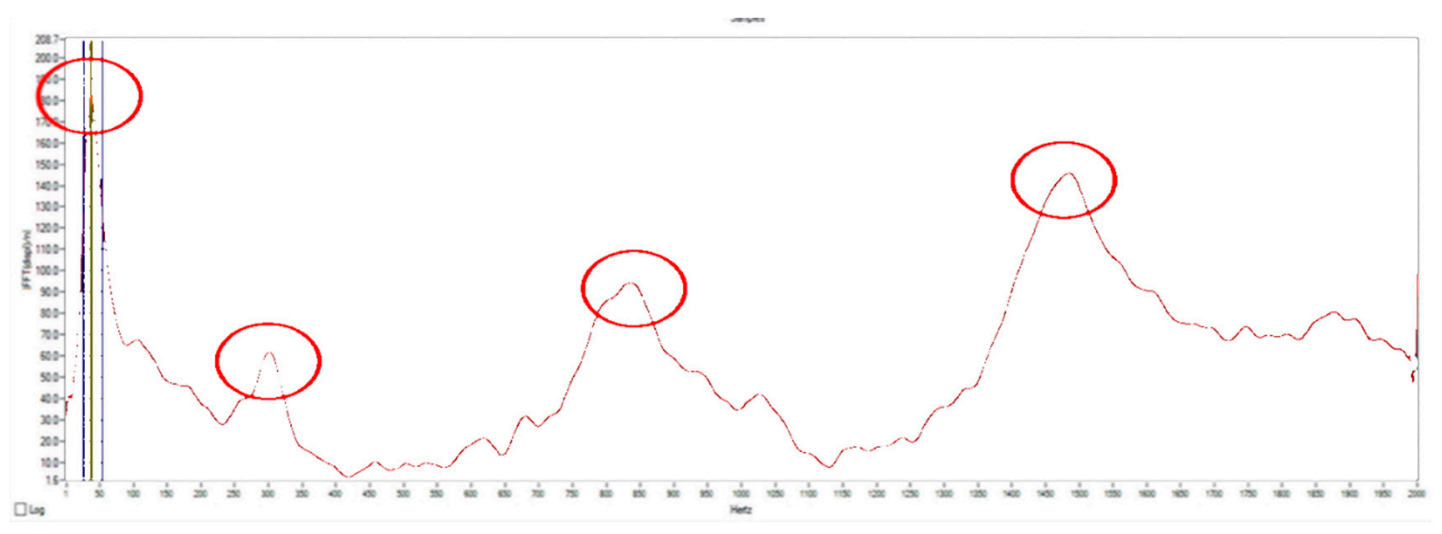

Figure 3. Frequency response function of oscillating specimen: Identification of resonance peaks.

\subsection{Results and Discussion}

From Figure 3, it is possible to highlight the most relevant peaks of the FRF measured for the oscillating specimen of Figure 2. In the case under examination, it can be seen that the peaks of greater amplitude are at about 50,300, 800, and $1450 \mathrm{~Hz}$. The latter, however, has not been analyzed, since it goes well beyond the frequency range of interest, which is $(0-500) \mathrm{Hz}$.

The Resonance Test software identifies and calculates for each peak: The resonance frequency, the loss factor $\eta$, and damping ratio $\zeta$.

Being unknown the real fiber orientation for the components under analysis, the values of $\eta$ and $\zeta$ adopted are calculated by averaging the values in correspondence of three different orientations of the fibers $\left(0^{\circ}, 45^{\circ}, 90^{\circ}\right)$.

The results show that, over the entire frequency range analyzed, there is an increase in damping values compared to a glass fiber-reinforced composite material.

These frequency variable damping values are used for subsequent analyses, such as the calculation of inertance, dynamic stiffness, and vibroacoustic transfer function.

\section{Experimental-Numerical Correlation on FRF of a Real Component}

Experimental tests were conducted in order to acquire the frequency response functions at specific points on a component made of PP $23 \mathrm{CF}$, through the following steps:

- the tested component is the central rear aerodynamic guard of the Alfa Romeo Giulia car, dimensions are $1370 \times 537 \times 2.5 \mathrm{~mm}$;

- the component was suspended from a rigid frame by means of $50 \mathrm{~cm}$ long low stiffness elastic tie rods,

- the instrument that excites the structure is an instrumented hammer, with a load cell impedance of $3.96 \Omega$

- the system response was recorded with a PCB HT 356B21 piezoelectric accelerometer.

The accelerometer was glued in each point of analysis, and, in the same point, the component was excited with an instrumented hammer (Figure 4). 


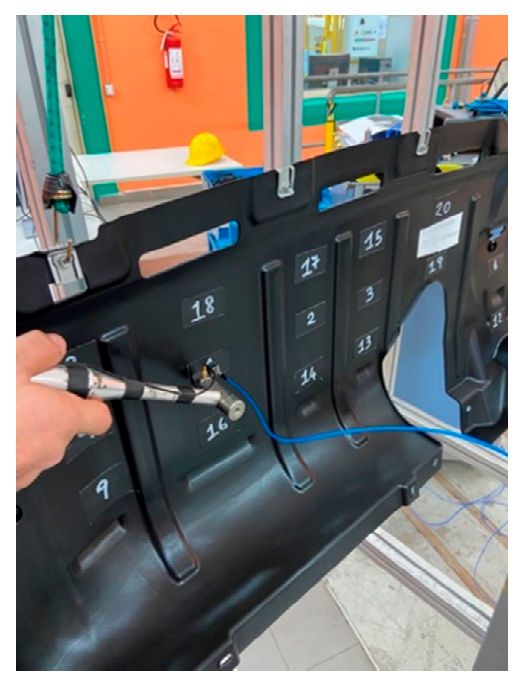

Figure 4. Instrumented hammer and shelter component.

For each point, three shots were given in the normal direction to the component (in case of an overload or an underload, the software automatically rejects the measurement), the hammer input and accelerometer output signals were post-processed with the LMS Test.Lab-Impact Testing software (Munich, Germany).

Three blow repetitions are necessary for each acquisition point in order to evaluate the coherence function $\gamma$, which must be close to 1 for the entire frequency range of interest, in the case under consideration from 0 to $400 \mathrm{~Hz}$.

Twenty FRF curves were exported, one for each acquisition point, in order to perform an experimental numerical correlation on a sufficient number of points.

The Frequency Response calculation was performed through post-modal reconstruction (Real Eigenvalue Analysis-SOL 103-Nastran), exciting the component in a point and calculating the acceleration vs. frequency at the same point.

The composite material was modeled as homogeneous and the preprocessing was carried out using the Altair HyperMesh software [21].

The shelter components are all plastic made and were modeled by using two-dimensional shell elements.

A mesh consisting mainly of Quad elements and a small percentage of Tria elements, with an average size of $3.5 \mathrm{~mm}$ was created (Figure 5).

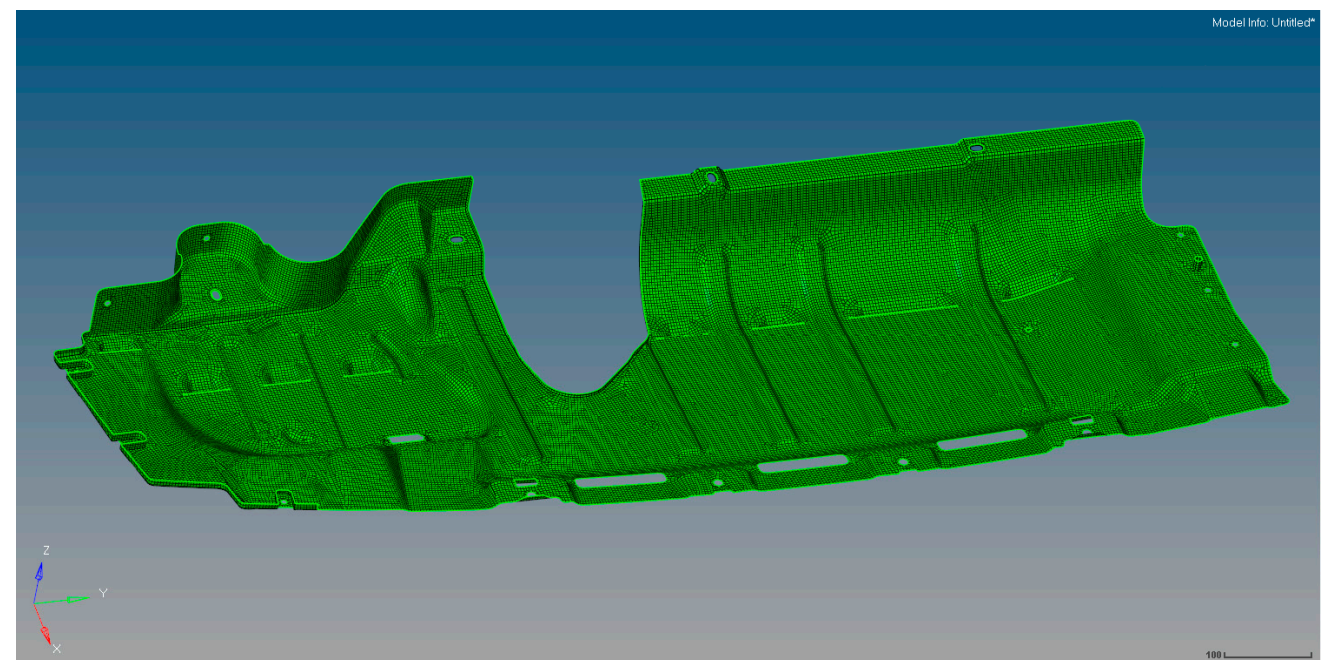

Figure 5. Aerodynamic guard mode with highlight of the adopted mesh. 
Numerical and experimental inertances, in the frequency range [0-400] Hz, are explicitly shown in Figure 6 for a couple of points.



Point N. 13

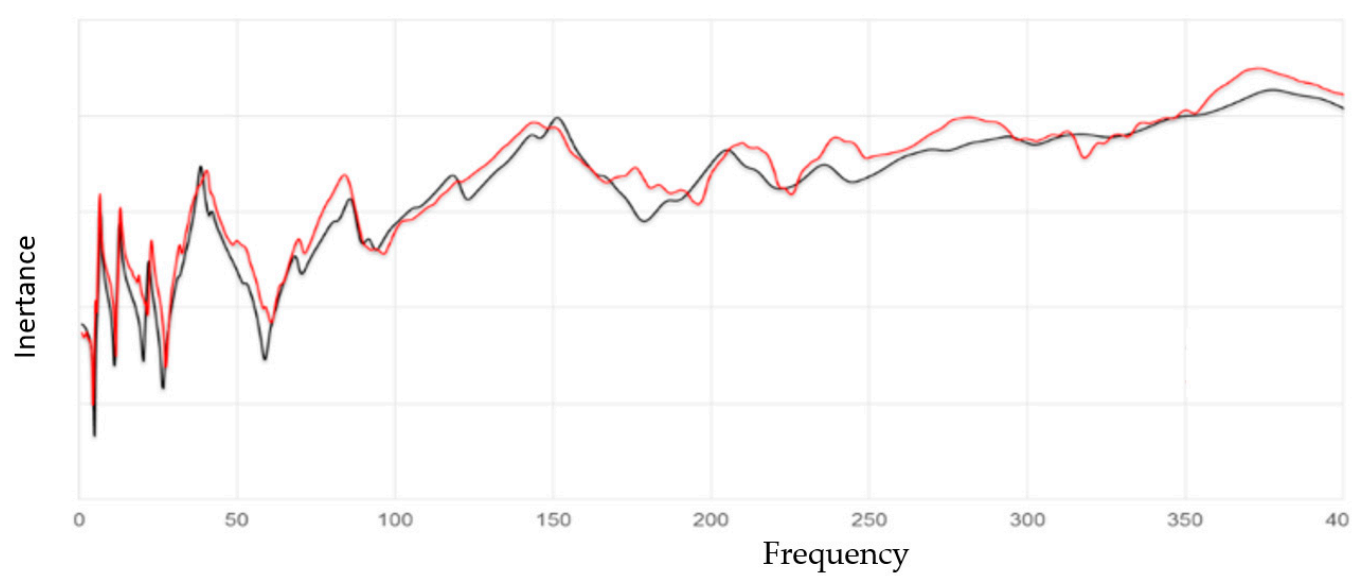

Point N. 14

Figure 6. Numerical (black line) and experimental (red line) inertances vs. frequency (Hz) for the shelter component at points N. 13 and 14 (see Figure 4).

To numerically evaluate the numerical-experimental correlation, the Frequency Response Assurance Criterion (FRAC) was chosen (Equation (4)), its values ranging in the interval [0-1]: A FRAC value equal to 1 indicates an optimal correlation and values greater than 0.90 are considered satisfactory.

$$
F R A C=\frac{\left[\sum_{i=50 \mathrm{~Hz}}^{400 \mathrm{~Hz}}\left(F R F_{s p}(i)_{j, k} * F R F_{n u m}(i)_{j, k}\right)\right]^{2}}{\left[\sum_{i=50 \mathrm{~Hz}}^{400 \mathrm{~Hz}}\left(F R F_{s p}(i)_{j, k}\right)^{2}\right] *\left[\sum_{i=50 \mathrm{~Hz}}^{400 \mathrm{~Hz}}\left(F R F_{\text {num }}(i)_{j, k}\right)^{2}\right]}
$$

In the case in question, the obtained FRAC values were greater than 0.9 for all points with a coherence function close to 1 (the coherence function $\gamma^{2}$. is obtained by the ratio between two spectral density functions calculated from different experimental data). Such results allowed concluding that the virtual component, characterized as a homogeneous material, with the mechanical and damping properties measured experimentally, satisfactorily approximates reality.

The next step is the modeling of the car roof of the Alfa Romeo 4C car. 


\section{Evaluation of the Vibroacoustic Behavior of the Alfa Romeo 4C Car Roof}

Having carrying out the experimental-numerical correlation of the PP23CF plant-fiber composite material, the next step is to evaluate its possible use for a coupe sports car roof (Figure 7).

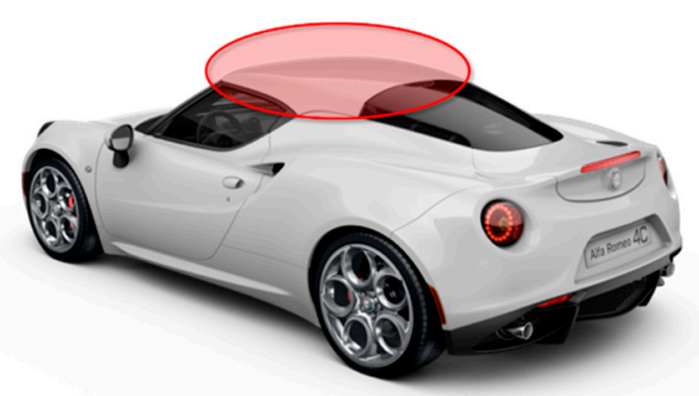

Figure 7. Alfa Romeo 4C car, with highlight of the roof.

\subsection{FE Model}

The finite element model used (Figure 8) consists of a mesh characterized as described in Table 1.

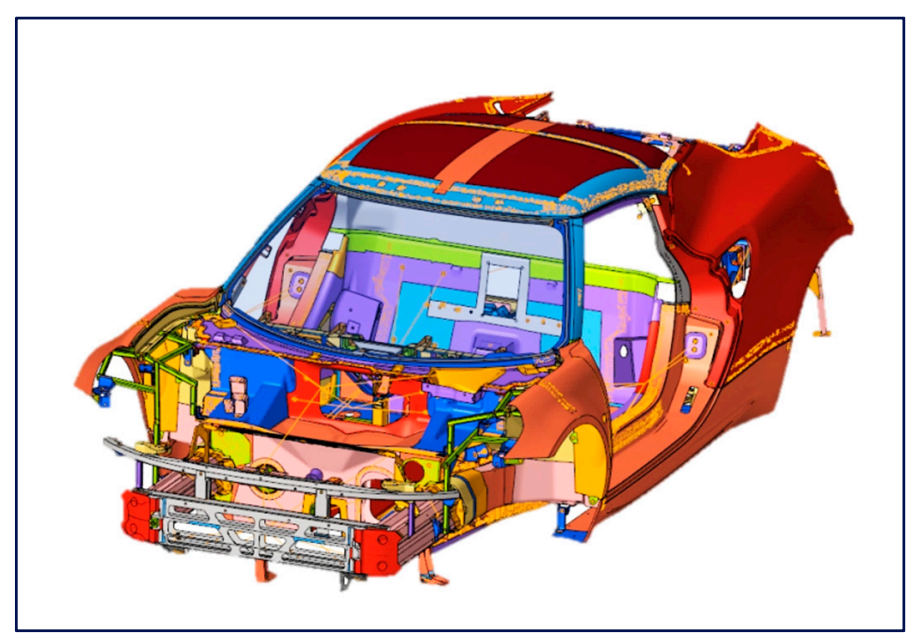

Figure 8. 4C car FE model.

Table 1. Mesh details and mass of 4C car model.

\begin{tabular}{cc}
\hline Total number of nodes & $\sim 1,200,000$ \\
\hline Total number of elements & $\sim 2,400,000$ \\
\hline Average element size (mm) & 7.0 \\
\hline Total mass $(\mathrm{kg})$ & 413.1 \\
\hline
\end{tabular}

The car roof in question was originally composed of a fiberglass composite material with a variable thickness, ranging from 2.2 to $3.0 \mathrm{~mm}$ (Figure 9). 




Figure 9. Fiberglass composite roof with highlight of variable thickness.

PP23CF material has a lower Young modulus than glass fiber material, but a lower density.

As regards the damping, the TCA material data are available and are compared with the average damping values of the PP23CF, previously measured according to the ASTM E756 standard (Figure 10): It can be noted that the damping of PP23CF is triple than TCA.

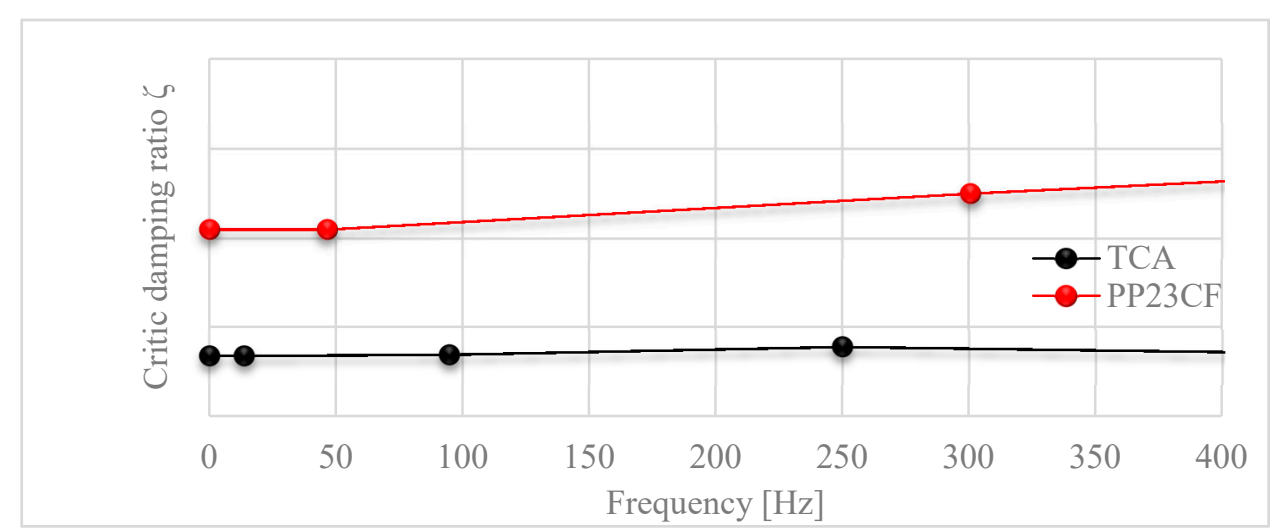

Figure 10. Critical damping of two different materials analyzed: Composite with glass fibers (TCA) and composite with vegetable fibers (PP23CF).

\subsection{Static Stiffness}

The static stiffness of the PP 23 FC pavilion with unchanged geometry was calculated at different points.

In particular, nine points uniformly distributed, were considered on the pavilion (Figure 11).

The static stiffness of the pavilion is evaluated as:

$$
k_{\text {stat }}=\frac{F}{x}
$$

where $F$ is the normal (unitary) force applied to the pavilion at the specific point and $x$ is the displacement of the same point in the direction of excitation.

The points are suitably defined with the Hypermesh software, and the static stiffness is calculated with the Nastran code (Figure 12), in particular with a SOL 101 (Linear Static Analysis).

Static stiffness was calculated for the nine points for the three materials, i.e., SMC, TCA and PP23CF (Figure 13). 


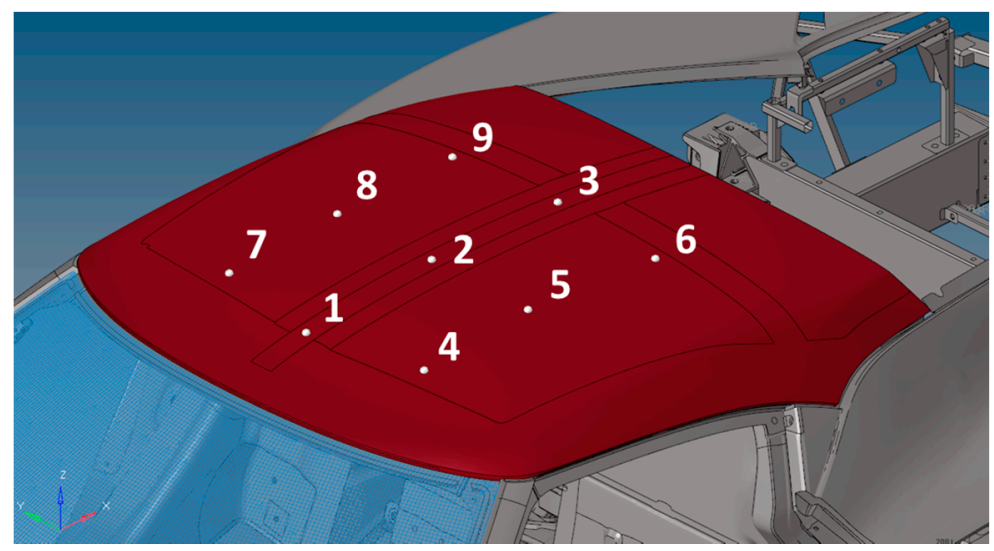

Figure 11. Monitoring point on the pavilion of $4 \mathrm{C}$ car.

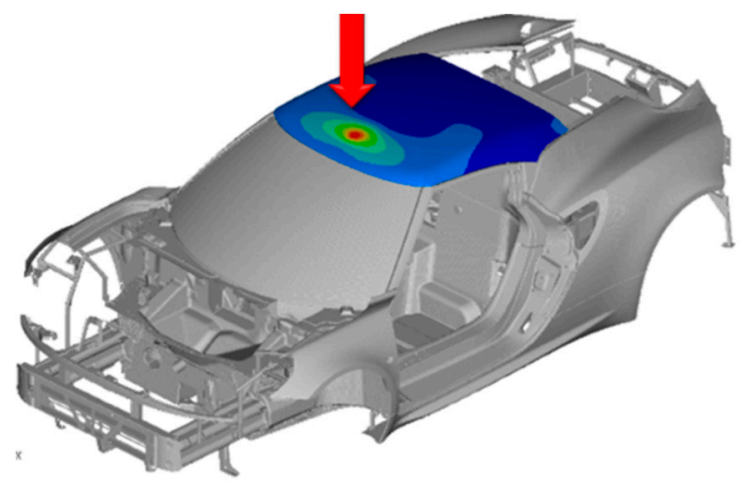

Figure 12. Displacement of point 1 of the pavilion of $4 \mathrm{C}$ car.

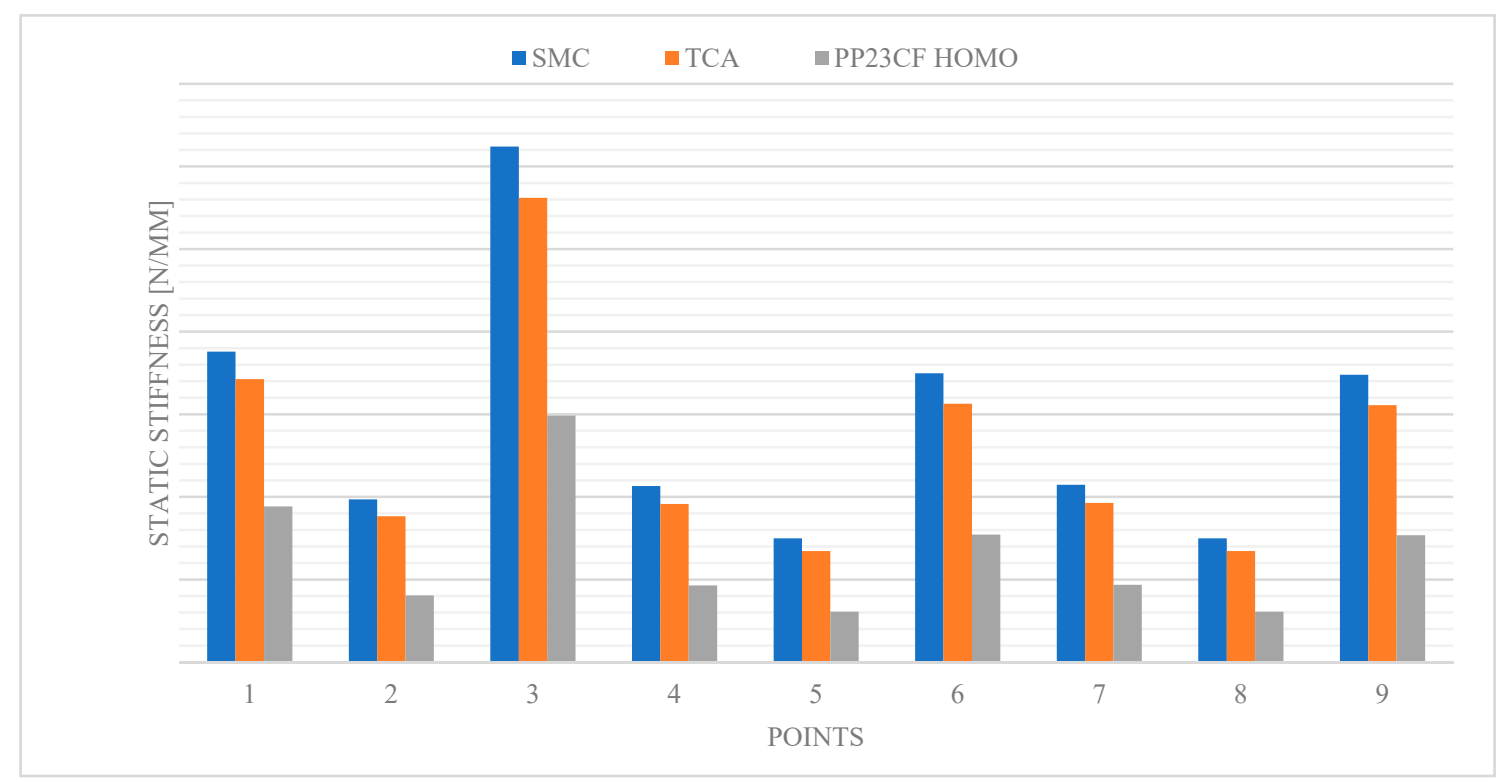

Figure 13. Static stiffness for every single point (see Figure 11) and material under analysis.

From the results, it is possible to observe that changing from the glass-reinforced material to the biocomposite, there is a halving of the static stiffness, due to the lower value of Young's modulus compared to the PP23CF material. 


\subsection{Car Roof Optimization}

In order to recover the static rigidity of the pavilion, the design of the component had to be optimized, as the only increase of thickness would cause exceeding the weight of the pavilion made of fiberglass.

The design proposed during the optimization was based on a series of ribs, $10 \mathrm{~mm}$ high and $2 \mathrm{~mm}$ wide, along the entire surface of the pavilion (Figure 14) and a reduction of its thickness (Figure 15) in order to reduce the weight.

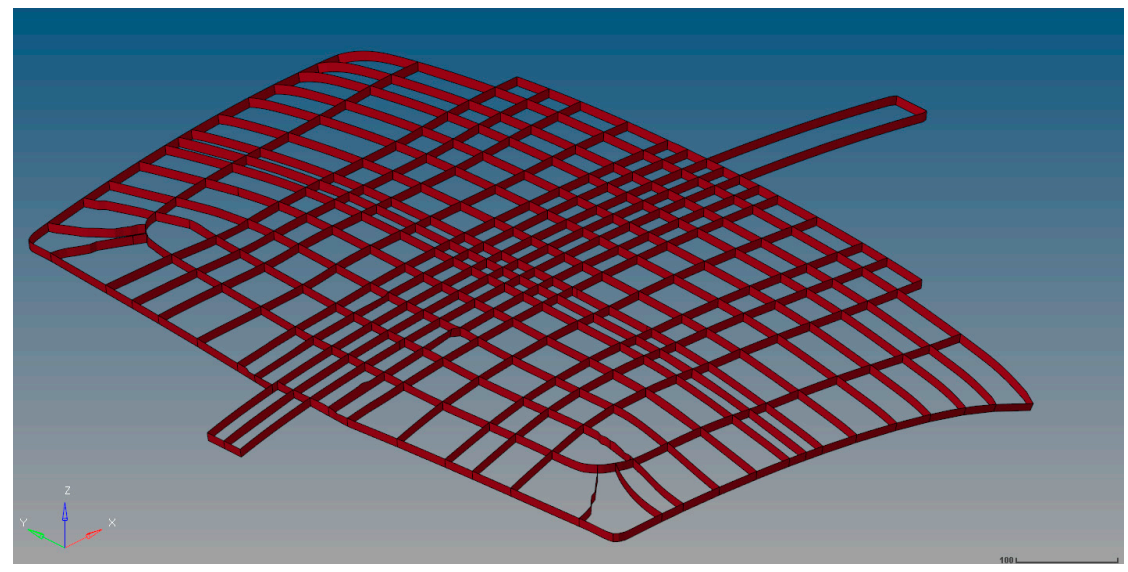

Figure 14. Car roof stiffening in the new optimized PP23CF configuration.

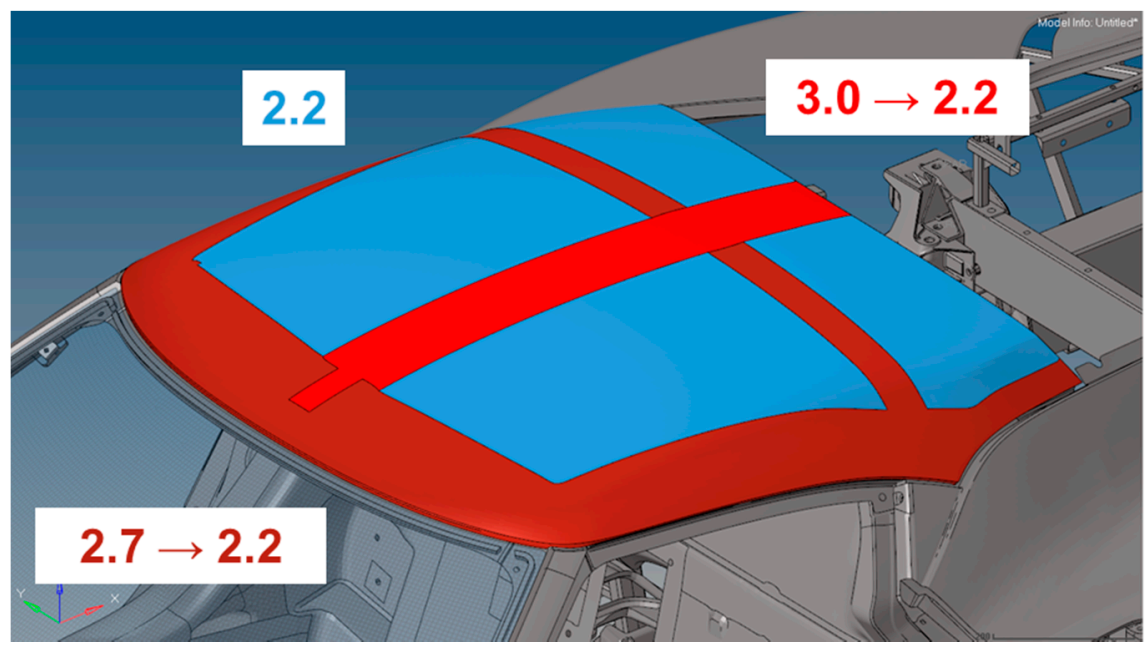

Figure 15. Pavilion thickness variation in the new optimized PP23CF configuration.

The realization of the pavilion thus constituted is possible if the component is made by injection. It can be seen that the weight of the optimized pavilion (Figure 16) was 7\% higher than the base component made of the same PP23CF material, but it was $31 \%$ lower than the SMC pavilion and 14\% lower than the TCA pavilion. Moreover, the static stiffness was recovered in all the points considered in the roof (Figure 17). 


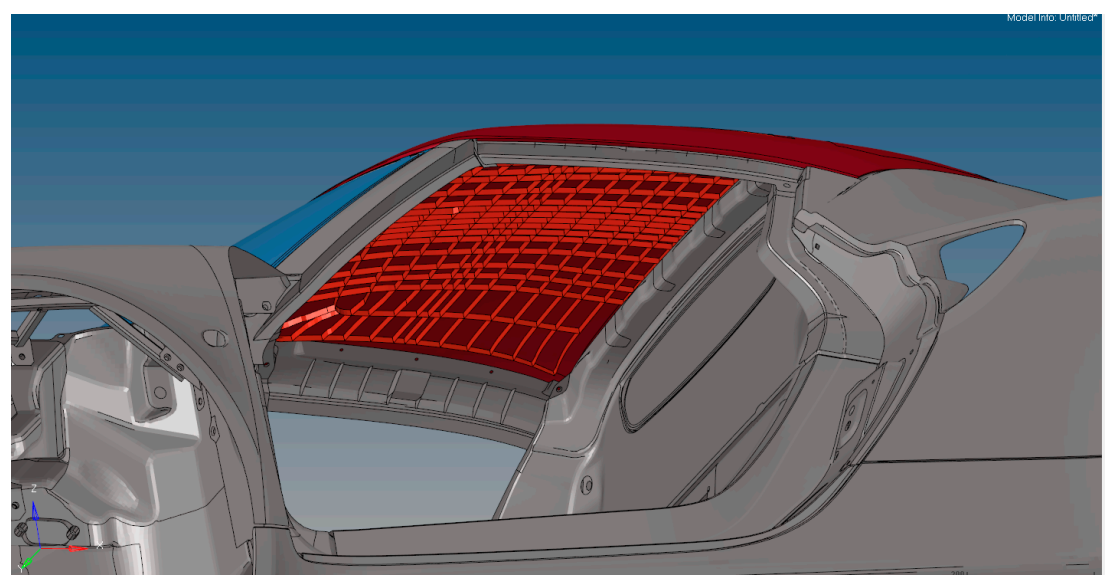

Figure 16. PP23CF optimized car roof-bottom view.

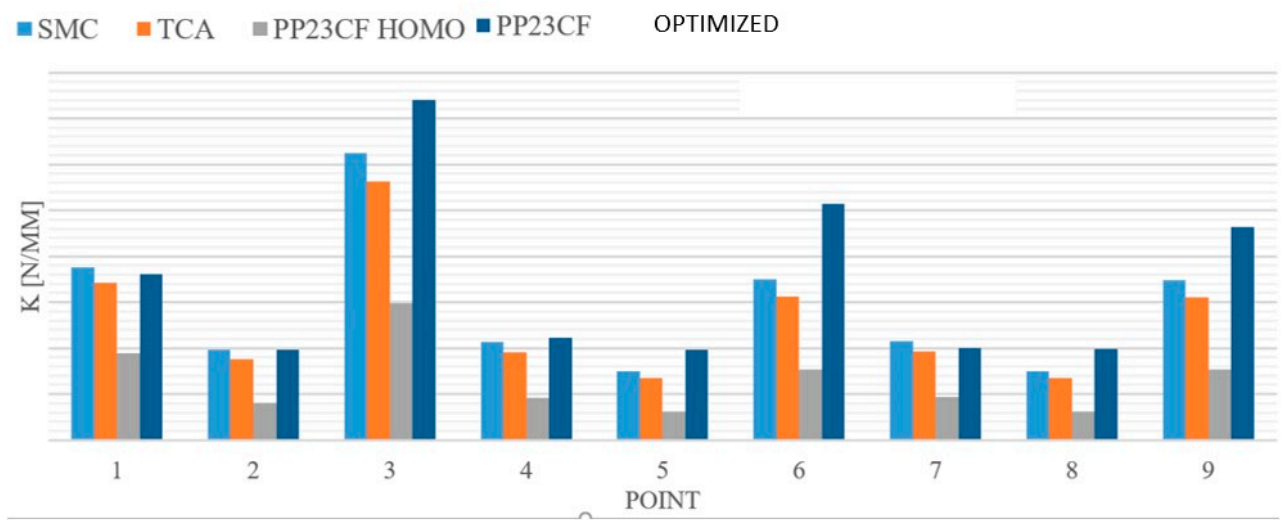

Figure 17. Static rigidity in the points of the car roof (Figure 11) for different materials ("PP23CF optimized" makes reference to the new stiffened configuration).

\subsection{Dynamic Stiffness}

The dynamic stiffness is defined as the ratio between the dynamic force and the corresponding displacement. It characterizes the elastic deformation of a component subject to a dynamic load.

Therefore, after the evaluation of the static stiffness, the next comparison between the different materials is based on their respective dynamic stiffness in the frequency range $50-400 \mathrm{~Hz}$.

This analysis was carried out with the Nastran code, running a SOL 103 (Real Eigenvalue Analysis). The structure is excited in the frequency range with a unitary force and, at the same point, the corresponding displacement is recorded. Frequencies below $50 \mathrm{~Hz}$ are not considered because the global modes of the car predominate on the vibration modes of the pavilion.

In Figure 18 the dynamic stiffness of the PP23CF component with the optimized geometry is compared with that of the component in TCA.

The results were post-processed with the HyperView software, showing, for all the considered points of the pavilion, an increase in the dynamic rigidity provided by the new material for the entire frequency range considered $(50-400 \mathrm{~Hz})$. Such an outcome is positive and plausible as the static rigidity of the component had already been recovered. 

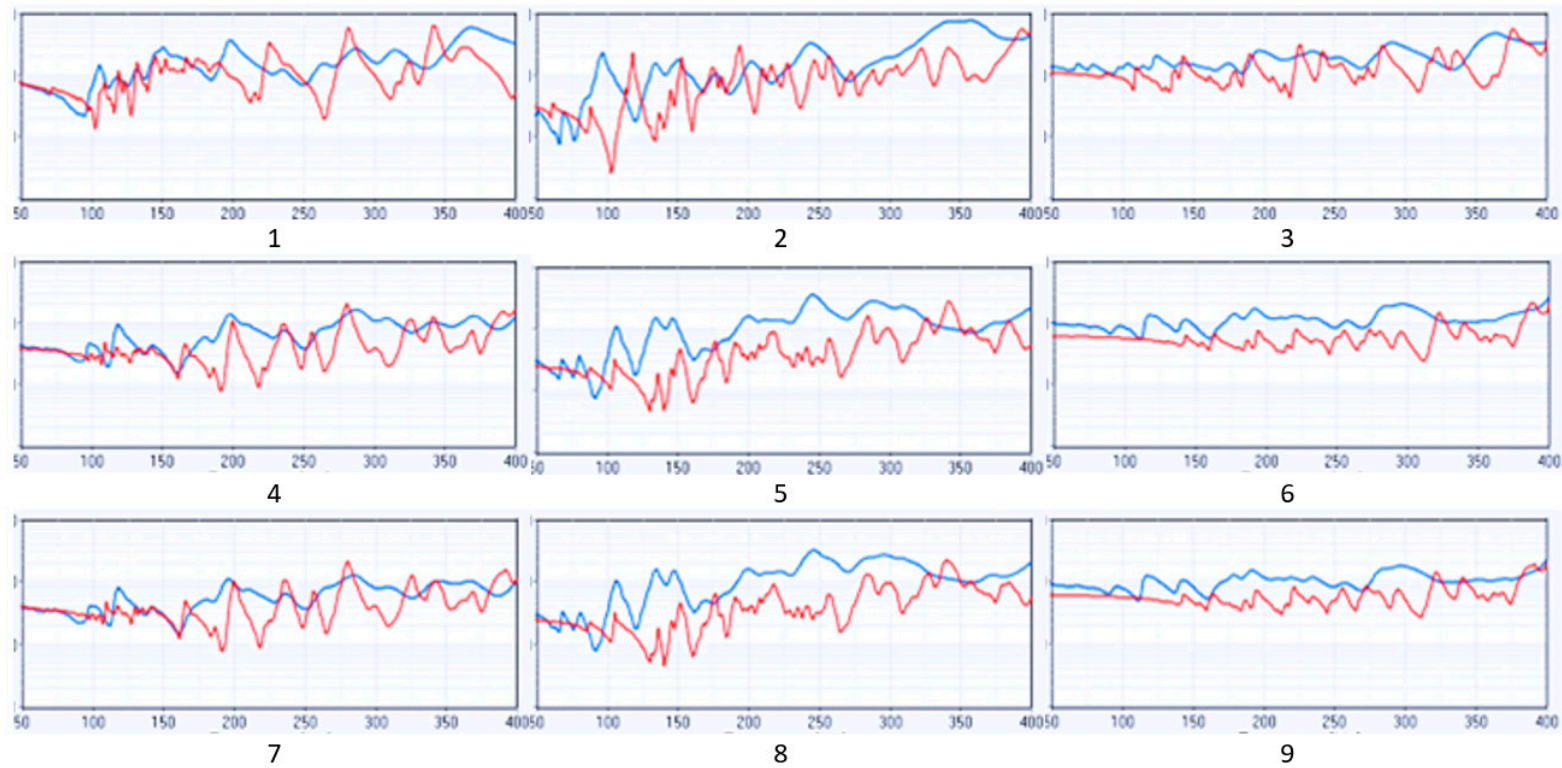

Figure 18. Dynamic stiffness of the car roof vs. frequency in each monitoring point (Figure 11): PP23CF component, with the optimized structure (blue line) and TCA component (red line).

\subsection{Modal Analysis}

In order to assess the frequency modes and their shapes, a modal analysis was necessary but, if applied to the entire vehicle, including every subcomponent, would have involved a significant computational burden in terms of memory requirements, to store nearly 700 mode shapes in the range $0-400 \mathrm{~Hz}$. For this reason, in order to be able to extract only the vibrating modes of the pavilion, it was necessary to perform a calculation of the pavilion inertia and, from the graphic display of the peaks of inertances, pinpoint the resonant frequencies corresponding to pavilion modes.

The procedure was implemented as follows:

- calculation of pavilion inertance with a SOL 103 analysis,

- graphical display of inertance peaks with highlight of the corresponding frequencies,

- modal analysis of the complete model,

- selection of the mode shapes whose frequencies are close to those identified by inertance peaks (Figure 19).

The analysis was restricted to the vibration modes up to $160 \mathrm{~Hz}$ because, beyond this frequency, the modes become local and consequently not involving the pavilion.

Such an approach was applied to the pavilion made of TCA and PP23CF (Figure 20).

For the pavilion made of composite material PP23CF OPTIMIZED it is possible to observe:

- $\quad$ an increase in the number of resonant modes and a shape modification at lower frequencies $(70-100 \mathrm{~Hz})$ due to the geometric modifications of the pavilion,

- a reduction in the number of resonant modes at higher frequencies $(f>130 \mathrm{~Hz})$

Usually, an increase in the number of resonant modes at lower frequencies is not positive, however, it is to be verified whether such modes are excited in the normal operation of the vehicle and if there is a coupling with the cavity modes. 


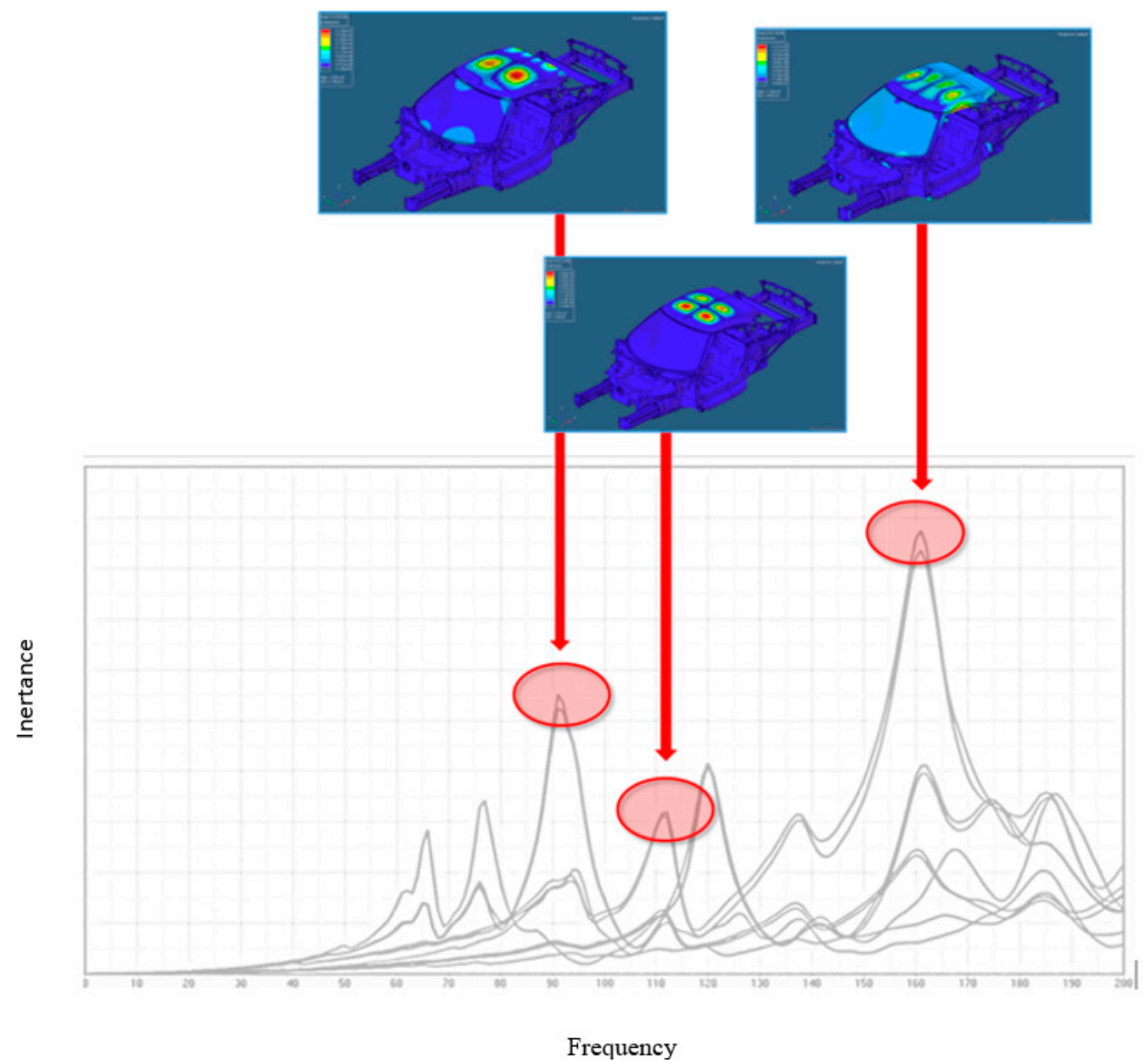

Figure 19. Identification of $4 \mathrm{C}$ car pavilion modes: Inertances vs. frequency.



PP23CF OPTIMIZED

Figure 20. Car roof modal shapes and related eigenfrequencies when considering the two materials, TCA and PP23CF OPTIMIZED, for the pavilion. 


\subsection{Modeling of the Acoustic Cavity}

In order to evaluate the cavity modes and vibroacoustic transfer functions, the modeling of the acoustic cavity of the passenger compartment was performed (Figure 21).

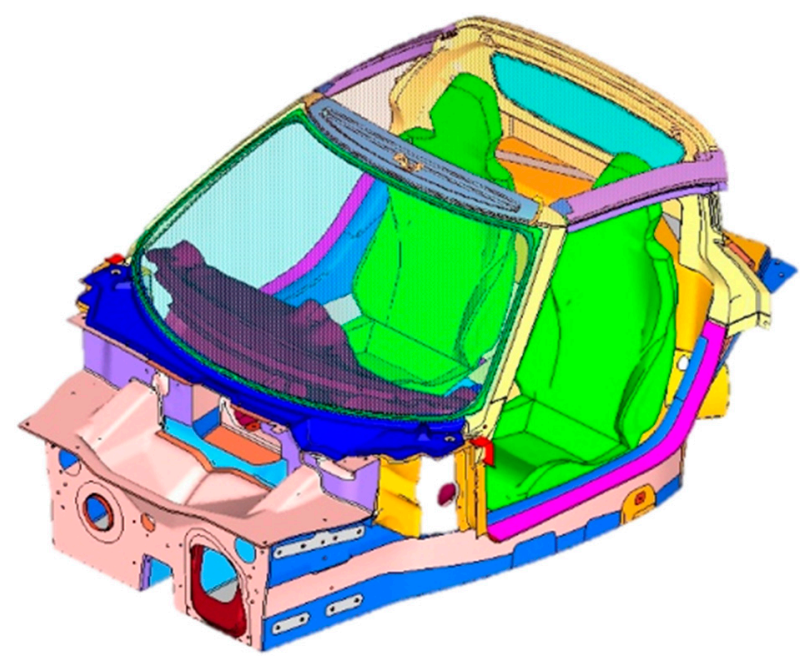

Figure 21. Passenger compartment with highlight of the acoustic cavity.

This fluid volume was discretized by FEM with the ANSA software, discretizing it with cubic solid elements of variable size (Table 2).

Table 2. Size of the acoustic cavity FEM elements and total number of nodes and elements.

\begin{tabular}{cc} 
Average size of internal cavity elements $(\mathrm{mm})$ & 40 \\
Average size of external cavity elements $(\mathrm{mm})$ & 20 \\
Average size of seat elements $(\mathrm{mm})$ & 10 \\
Total number of nodes & $\sim 180,000$ \\
Total number of elements & $\sim 230,000$ \\
\hline
\end{tabular}

The choice of the maximum size for the cavity mesh (Figure 22) was made by considering six elements per wavelength:

$$
\lambda=\frac{1}{6} \frac{c}{f_{\max }}=\frac{1}{8} \frac{331 \mathrm{~m} / \mathrm{s}}{900 \mathrm{~Hz}} \approx 50 \mathrm{~mm} .
$$

where $f$ is the maximum frequency of interest, equal to $900 \mathrm{~Hz}, c$ is the speed of sound in the fluid of interest, in this case, air.

After having discretized the cavity, a FEM modal analysis was carried out to find out the cavity modes (Figure 23). The analysis was carried out with the Nastran SOL 103 in the frequency range $0-900 \mathrm{~Hz}$. From Figure 23, it is possible to highlight a first longitudinal mode at $107.6 \mathrm{~Hz}$ and a second transversal mode at $131.6 \mathrm{~Hz}$, then a mixed local (involving the anterior part of the cavity transversely)-global (involving in an oblique direction the remaining part of the cavity) mode at $182.1 \mathrm{~Hz}$, etc. (increasing the frequency, the modes assume a more complex shape and, on the other hand, progressively become of reduced interest for our purposes). 


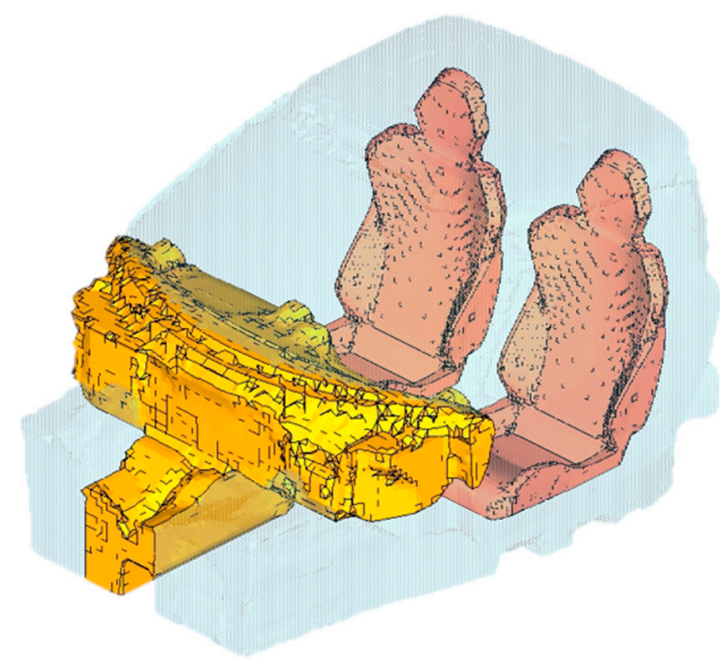

Figure 22. Acoustic FEM mesh of $4 \mathrm{C}$ car the passenger compartment.
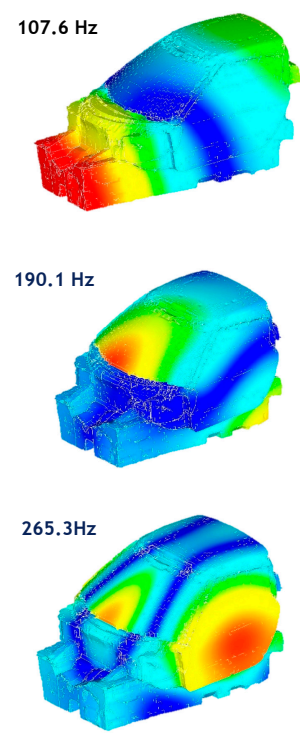
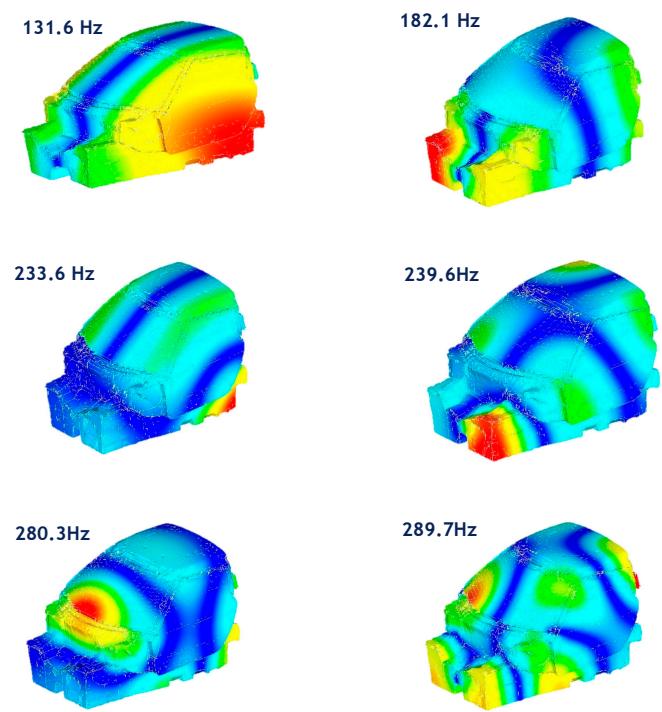
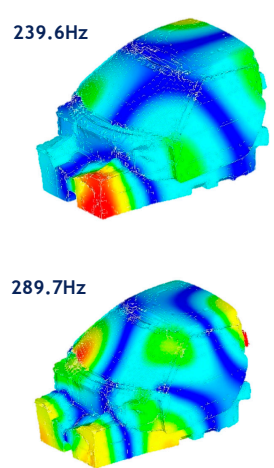
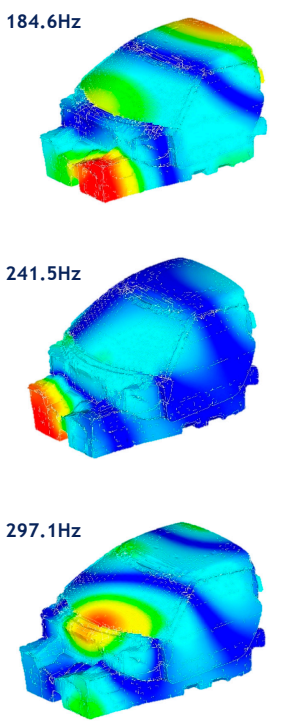

Figure 23. Cavity modes of passenger compartment.

\subsection{Fluid-Structure Coupling}

To evaluate possible couplings of the pavilion's vibrating modes and cavity's vibrating modes, it is necessary to evaluate and compare their resonant frequencies and mode shapes.

The pavilion was energized in the center (point 2), and the inertances between 0 and $400 \mathrm{~Hz}$ were calculated for both PP23FC and TCA (Figure 24).

The PP23CF pavilion presents two structural modes at low frequencies, up to the frequency of $80 \mathrm{~Hz}$. However, the absence of cavity modes in the frequency range $0-80 \mathrm{~Hz}$ and the high damping level provided by the new material should protect against very significant in-cabin sound pressure increases.

Some problems could come in the interval between $120 \mathrm{~Hz}$ (structural mode) and $132 \mathrm{~Hz}$ (cavity mode), not only because of the vicinity of the two peaks but also because of the similarity of related mode shapes. Much relevant in this case is the structural damping value that should be sufficiently high to smooth the structural peak within a small frequency interval. 


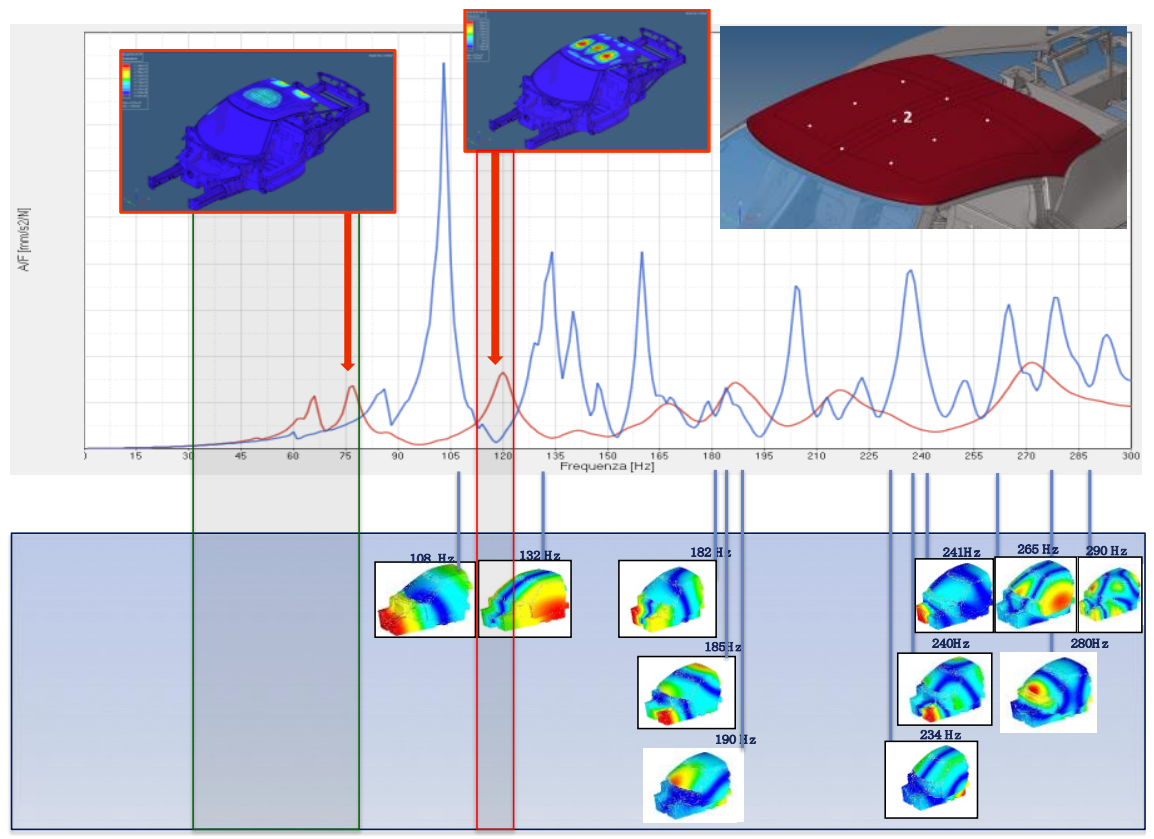

Figure 24. Analysis of potential coupling between the cavity and structure modes, considering the pavilion made of PP23FC OPTIMIZED (red line) and TCA (blue line).

\subsection{Vibroacoustic Transfer Functions}

The Vibroacoustic Transfer Functions, FdT, (also called " $\mathrm{P} / \mathrm{F}$ ") represent the ratio between the sound pressure levels at the listening points inside the passenger compartment and the force levels that, applied at the body entry points, generated them. They characterize the acoustic response of the car body evaluated at the standard listening points (from a customer perspective), in correspondence of the driver's right ear and the passenger's left ear. In the case in question, since the car is the Alfa Romeo $4 \mathrm{C}$, the rear passenger is not present.

The coordinates of the driver listening points are calculated with respect to the seats (Figure 25) as in the followings:

- $\mathrm{X}$ : Back seat intersection,

- Y: Center line back $+20 \mathrm{~cm}$,

- $\quad \mathrm{Z}$ : Back seat intersection $+70 \mathrm{~cm}$.

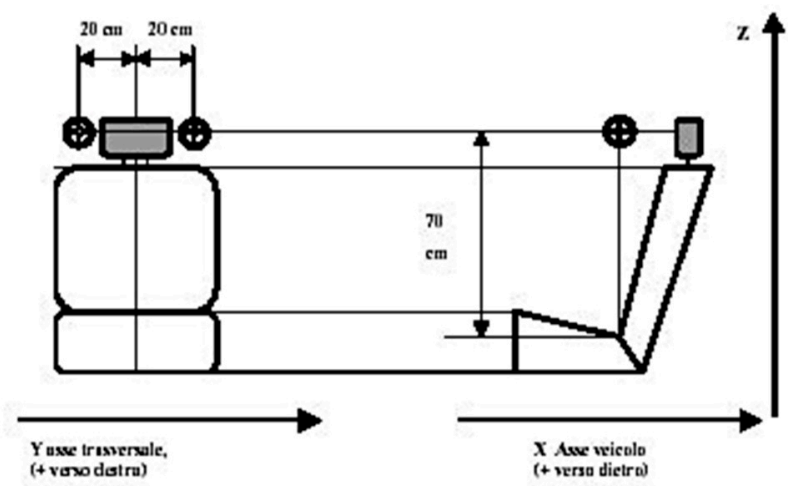

Figure 25. Positioning of listening point inside passenger compartment.

In order to observe and compare the acoustic contribution in the aforementioned points provided by the PP23CF OPTIMIZED or TCA pavilion, the point where exciting the structure was chosen in the pavilion center (Figure 26). 


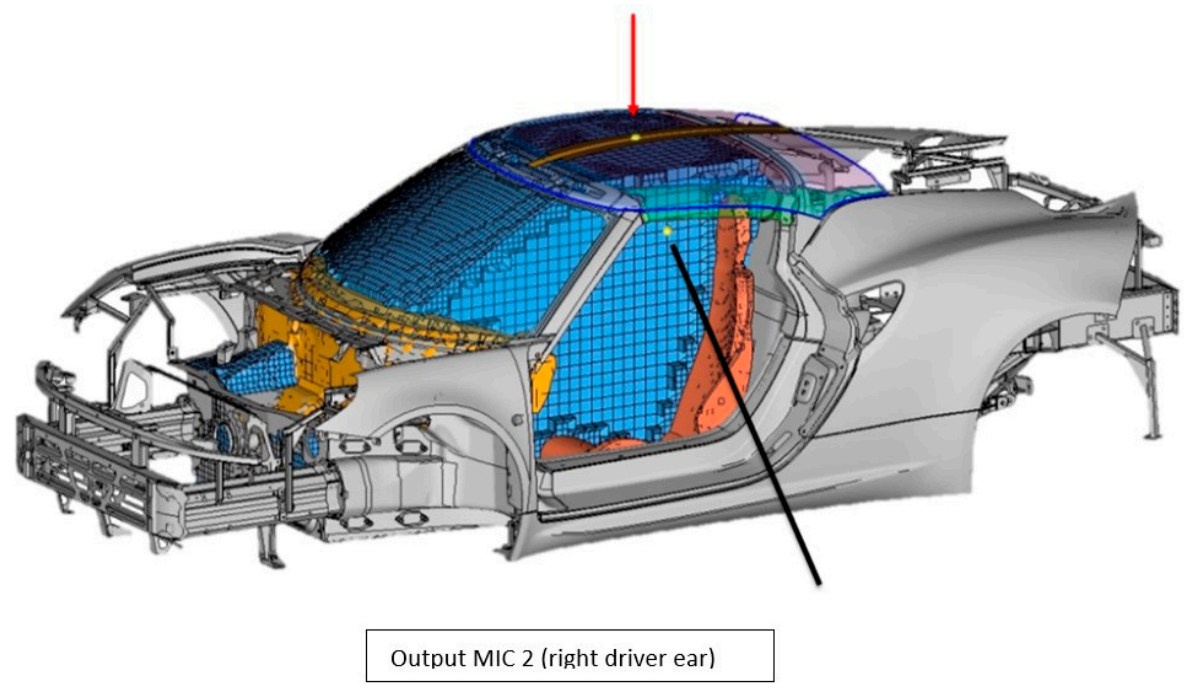

Figure 26. Hall center input where exciting the structure and measurement point for sound pressure level (MIC 2).

The vibroacoustic transfer functions were calculated with the Nastran SOL 111 Modal Frequency Response Analysis (according to FCA internal rules).

From the graph in Figure 27, it is possible to observe:

- an improvement in almost the entire frequency range provided by the new material,

- a worsening limited to the very low frequencies, where the PP23CF pavilion strongly vibrates, when exciting the pavilion in the center.

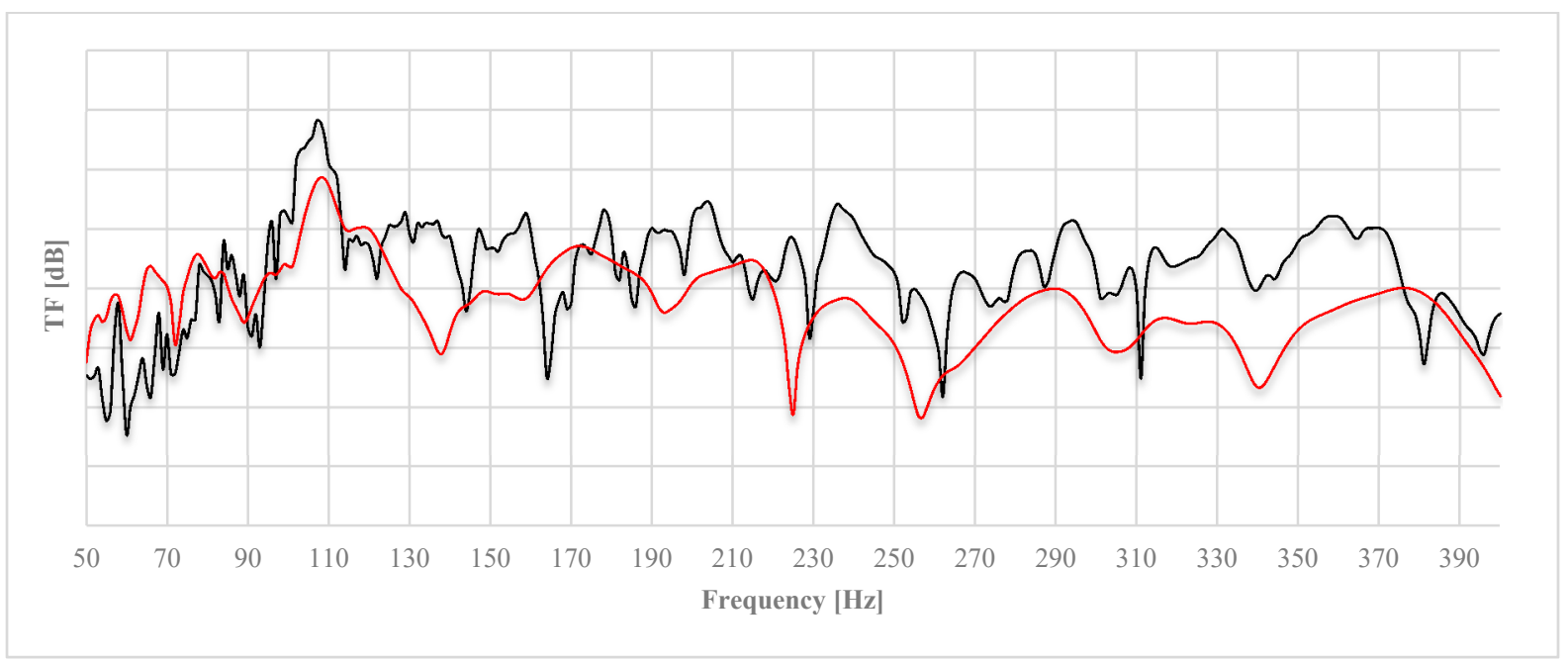

Figure 27. Vibroacoustic transfer functions (TF) from the car roof center to the ear node for TCA (black line) and PP23CF OPTIMIZED (red line).

Moreover, in order to reproduce the working conditions of the vehicle, it was decided to excite the shock absorber attachment point, which is the most critical point, on which all the weight of the vehicle rests (Figure 28). 


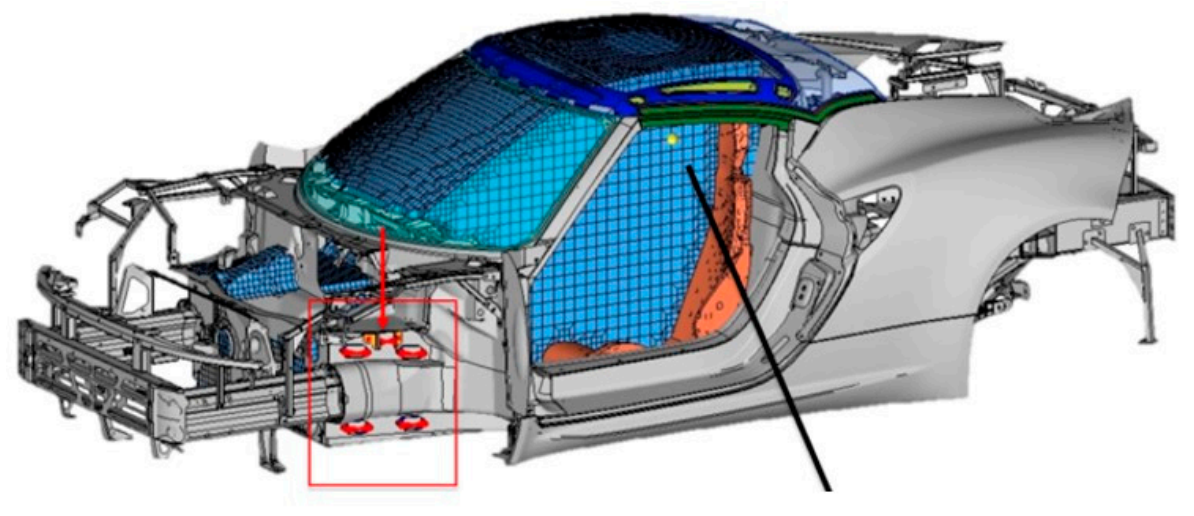

MIC 2

Figure 28. Force input at front shock absorber connection (in red) and measurement point for sound pressure level (MIC 2).

The vibroacoustic transfer functions were assessed in the same way, evaluating both the contribution of the pavilion alone (Figure 29) and the vibroacoustic transfer functions, which include all the contributions of the panels adjacent to the cavity (Figure 30).

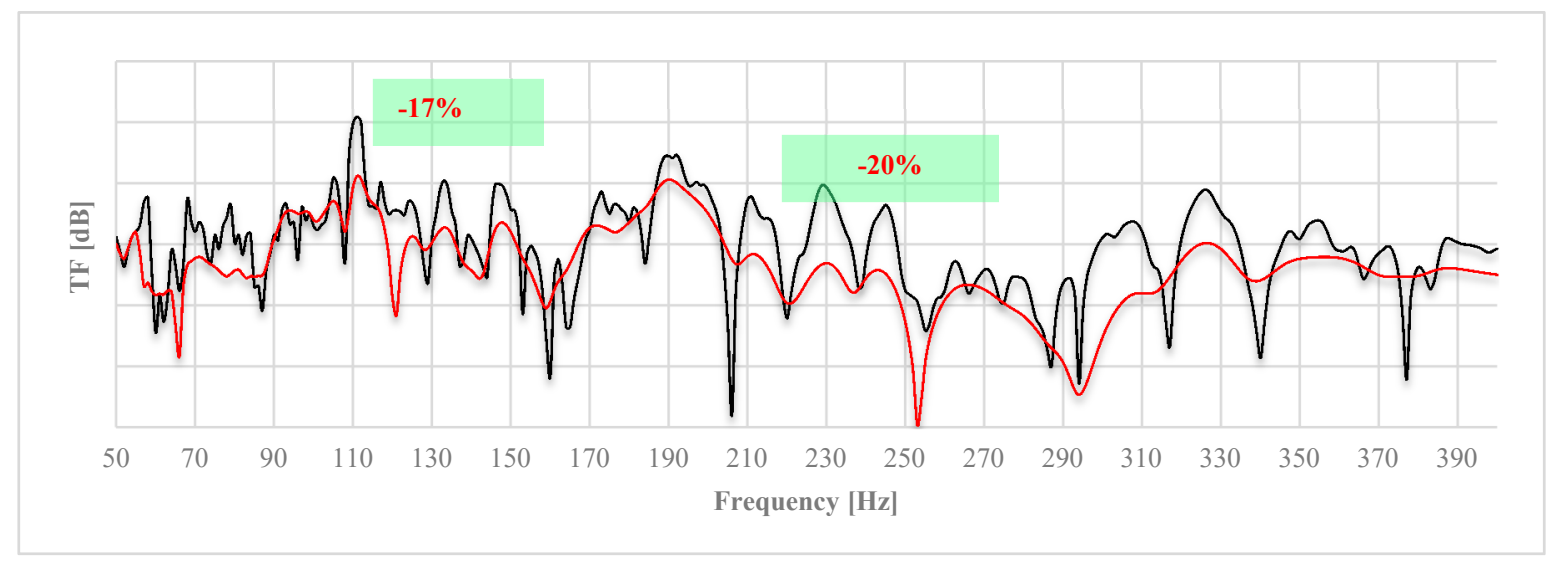

Figure 29. Vibroacoustic transfer functions (TF) from the shock absorber attachment to the ear node (MIC 2)—contribution from the pavilion only, considering the two materials: TCA (black line) and PP23CF OPTIMIZED (red line).



Figure 30. Vibroacoustic transfer functions (TF) from the shock absorber attachment to the ear node (MIC 2)—contribution of all panels, for pavilion made of TCA (black line) and PP23CF OPTIMIZED (red line). 
From the graphs in Figures 29 and 30, it can be observed that:

- there is no longer a deterioration at low frequencies because the involved vibration modes are not excited,

- there is an improvement in the whole frequency range, with improvement peaks of $9 \%$.

\section{Conclusions}

Taking advantage of the high damping capacity of the new material and thanks to a geometric optimization of the new pavilion, it was possible to circumvent the drawback related to the low value of the modulus of PP 23 CF longitudinal elasticity with respect to the fiberglass materials currently used in the automotive sector.

The low density of the new material and the geometric optimization lead to a $14 \%$ reduction in weight of the pavilion compared to the composite material with glass balls (TCA) and 31\% compared to the composite material with glass (SMC). The excellent damping capacity of the material led to an improvement in the vibroacoustic transfer functions, in particular for the front shock absorber entry point, a reduction in the peaks of these functions is observed from $1 \%$ to $9 \%$, in the entire frequency range of interest, from 50 to $400 \mathrm{~Hz}$.

Author Contributions: Conceptualization, L.C., R.C. and G.D.; methodology, L.C., R.C., G.D.; software, N.C. and L.C.; validation, N.C. and L.C.; formal analysis, N.C., L.C.; investigation, N.C., L.C.; resources, G.D.; writing —original draft preparation, N.C., R.C. and L.C.; writing—review and editing, R.C.; supervision, R.C., G.D. All authors have read and agreed to the published version of the manuscript.

Funding: This research received no external funding.

Institutional Review Board Statement: Not applicable.

Informed Consent Statement: Not applicable.

Data Availability Statement: Restrictions apply to the availability of these data. Data was obtained from Fiat Chrysler Automobile and are available from the authors with the permission of Fiat Chrysler Automobile.

Conflicts of Interest: The authors declare no conflict of interest.

$\begin{array}{ll}\text { Abbreviations } \\ \text { FEM } & \text { Finite Element Method } \\ \text { BEM } & \text { Boundary Element Method } \\ \text { GHG } & \text { Greenhouse Gas } \\ \text { GF } & \text { Glass Fibers } \\ \text { CF } & \text { Cellulose Fiber } \\ \text { PP 23 CF } & \text { Polypropylene 23 Cellulose Fibers } \\ \text { CRF } & \text { Fiat Research Center } \\ \text { FRF } & \text { Frequency Response Function } \\ \text { FRAC } & \text { Frequency Response Assurance Criterion } \\ \text { TCA } & \text { Titanate Coupling Agent } \\ \text { SMC } & \text { Sheet Molding Composite } \\ \eta & \text { Damping loss factor } \\ \zeta & \text { Damping ratio } \\ f_{n} & \text { Resonant frequency } \\ \Delta f_{n(-3 d b)} & \text { Half-power bandwidth of the n-th mode } \\ \gamma^{2} & \text { Coherence Function } \\ \lambda & \text { Wavelength }\end{array}$




\section{References}

1. Giannella, V.; Lombardi, R.; Pisani, M.M.; Federico, L.; Barbarino, M.; Citarella, R. A novel Optimization Framework to Replicate the Vibroacoustics Response of an Aircraft Fuselage. Appl. Sci. 2020, 10, 2473. [CrossRef]

2. Bianco, D.; Adamo, F.P.; Barbarino, M.; Vitiello, P.; Bartoccini, D.; Federico, L.; Citarella, R. Integrated Aero-Vibroacoustics: The Design Verification Process of Vega-C Launcher. Appl. Sci. 2018, 8, 88. [CrossRef]

3. Citarella, R.; Federico, L. Advances in Vibroacoustics and Aeroacustics of Aerospace and Automotive Systems. Appl. Sci. 2018, 8, 366. [CrossRef]

4. Smith, M.; Karatsovis, C. Predicting Noise on Marine structures, Malcom Smith \& Christos Karatsovis, ISVR, ESI Vibroacoustic User's Conference (VAUC); ESI: Köln, Germany, 2007.

5. Blanchet, D.; Matla, S. Building SEA Predictive Models to Support Vibroacoustic Ship Design; DAGA: Rotterdam, The Nederlands, 2009.

6. Citarella, R.; Armentani, E.; Giannella, V.; Parente, A.; Pirelli, M. FEM Substructuring for the Vibrational Characterization of a Petrol Engine. In SAE Technical Paper 2019-24-0059; SAE International: Warrendale, PA, USA, 2019. [CrossRef]

7. Klaerner, M.; Wuehrl, M.; Kroll, L.; Marburg, S. FEA-based methods for optimising structure-borne sound radiation. Mech. Syst. Signal Process. 2017, 89, 37-47. [CrossRef]

8. Citarella, R.; Landi, M. Acoustic analysis of an exhaust manifold by Indirect Boundary Element Method. Open Mech. Eng. J. 2011, 5, 138-151. [CrossRef]

9. Armentani, E.; Trapani, R.; Citarella, R.; Parente, A.; Pirelli, M. FEM-BEM Numerical Procedure for Insertion Loss Assessment of an Engine Beauty Cover. Open Mech. Eng. J. 2013, 7, 27-34. [CrossRef]

10. Adams, R.D.; Maheri, M.R. Damping in advanced polymer-matrix composites. J. Alloys Compd. 2003, 355, 126-130. [CrossRef]

11. Genovese, A.; Strano, S. Structural Behaviour and Vibroacoustic Analysis of a Composite Rail Vehicle Car Body Roof. World Congr. Eng. 2016, 2, 826-831.

12. Aamir, M.; Tolouei-Rad, M.; Giasin, K.; Nosrati, A. Recent advances in drilling of carbon fiber-reinforced polymers for aerospace applications: A review. Int. J. Adv. Manuf. Technol. 2019, 105, 2289-2308. [CrossRef]

13. Sarı̈ül, A.S.; Karagözlü, E. Vibroacoustic coupling in composite plate-cavity systems. J. Vib. Control 2018, 24, 2274-2283. [CrossRef]

14. Sepahvand, K. Spectral Stochastic Finite Element Vibration Analysis of Fiber reinforced Composites with Random Fiber Orientation, composite structures. Compos. Struct. 2016, 145, 119-128. [CrossRef]

15. Genc, G.; Körük, H. Investigation of vibroacoustic behaviours of luffa bio composites and assessment of their use for practical applications. In Proceedings of the 23rd International Congress on Sound and Vibration (ICSV23), Athens, Greece, 10-14 July 2016.

16. Mamtaz, H.; Fouladi, M.H.; Al-Atabi, M.; Narayana Namasivayam, S. Acoustic absorption of Natural Fiber Composites. J. Eng. 2016, 2016, 5836107. [CrossRef]

17. Sepahvand, K.; Scheffler, M.; Marburg, S.J.A.A. Marburg Uncertainty quantification in natural frequencies and radiated acoustic power of composite plates: Analytical and Experimental investigation. Appl. Acoust. 2015, 87, 23-29. [CrossRef]

18. Sarı̈ül, A.S.; Karagözlü, E. Vibroacoustic analysis of composite plates. In Journal of Physics: Conference Series; IOP Publishing: Bristol, UK, 2014; Volume 490.

19. Dhandole, S.D.; Modak, S.V. Review of Vibroacoustic analysis procedures for prediction of low frequency noise inside a cavity. In Proceedings of the 25th Conference \& Exposition on Structural Dynamics, Orlando, Florida, USA, 19-22 February 2007.

20. Samyal, R.; Singh, S.; Bagha, A.K. Modal analysis of composite panel at different fibre orientations. Mater. Today Proc. 2017, 16, 477-480. [CrossRef]

21. Altair Engineering. Hypermesh User Manual; Altair Engineering: Troy, MI, USA, 2011. 